\title{
Pharmacokinetic interaction of curcumin and glibenclamide in diabetic rats
}

\author{
P. R. Sakunthala Devi ${ }^{1}$, A. Gopala Reddy ${ }^{1}$, G. S. Rao ${ }^{2}$, C. S. V. Satish Kumar ${ }^{1}$ and G. Boobalan ${ }^{1}$
}

1. Department of Veterinary Pharmacology and Toxicology, College of Veterinary Science, Sri Venkateswara Veterinary University, Tirupati - 517 502, Andhra Pradesh, India; 2. Department of Veterinary Pharmacology \& Toxicology, NTR College of Veterinary Science, Sri Venkateswara Veterinary University, Tirupati - 517 502, Andhra Pradesh, India.

Corresponding author: P. R. Sakunthala Devi, email: sakunthalavet@gmail.com,

AGR: gopalareddy123@rediffmail.com, GSR: raogs64@rediffmail.com, CSVSK: satish513512@gmail.com, GB: bhupalvets@gmail.com

Received: 30-11-2014, Revised: 13-03-2015, Accepted: 19-03-2015, Published online: 19-04-2015

doi: 10.14202/vetworld.2015.508-511. How to cite this article: Sakunthala Devi PR, Gopala Reddy A, Rao GS, Satish Kumar CSV, Boobalan G (2015) Pharmacokinetic interaction of curcumin and glibenclamide in diabetic rats, Veterinary World 8(4); 508-511.

\begin{abstract}
Aim: The aim was to assess the pharmacokinetic (PK) interaction of curcumin and glibenclamide (GL) in diabetic rats.

Materials and Methods: Sprague-Dawley rats induced with diabetes were divided into 2 groups of six rats in each. Group I: $\mathrm{GL}(6 \mathrm{mg} / \mathrm{kg}$ po once daily) treatment in diabetic rats and group 2: Curcumin (50 $\mathrm{mg} / \mathrm{Kg}$ po once daily) + GL (dose as above) in diabetic rats. Blood samples were collected at pre-determined time intervals for kinetic analysis after the first and last oral dosing of GL for single and multiple dose studies, respectively. Plasma samples were assayed for GL concentration by high-performance liquid chromatography and PK parameters were analyzed.
\end{abstract}

Results: The half-life $\left(\mathrm{t}_{1 / 2}\right)$ and mean residence time (MRT) of GL were significantly increased in curcumin pre-treated rats as compared to GL alone in single and multiple dose studies. Similarly, the $\mathrm{V}_{\mathrm{dss}}$ was significantly increased in curcumin pre-treated rats in single dose study as compared to GL alone treated group, but no significant difference was observed in multiple dose kinetics.

Conclusion: The study revealed higher values $\left(t_{1 / 2}, M R T\right.$ and $\left.V_{d s s}\right)$ of GL in curcumin pre-treated group due to the inhibitory effect of curcumin on intestinal CYP3A4.

Key words: curcumin, glibenclamide, pharmacokinetics, CYP3A4

\section{Introduction}

Diabetes mellitus is a metabolic disorder featured by hyperglycemia and alterations in carbohydrate, fat and protein metabolism associated with absolute or relative deficiency of insulin secretion and/or insulin action. The incidence of the disorder is significantly increasing worldwide [1].

Glibenclamide (GL) is a second-generation sulphonylurea, which has been widely used in the management of Type- 2 diabetes [2]. GL kinetics showed a rapid and complete absorption (90-100\%) from the gastrointestinal tract [3]. GL is mainly metabolized by isozyme CYP3A4 [4]. The metabolites viz., 4-trans hydroxyl and 3-cis hydroxyl derivatives contribute no significant hypoglycemic action.

Curcumin is a low molecular weight polyphenol derived from turmeric [5]. It has a wide spectrum of biological functions such as antidiabetic, anti-inflammatory, immunomodulatory, and neuroprotective functions [6]. Herbal medicines that modulate intestinal and hepatic CYPs can alter the bioavailability and clearance of co-administered drugs [7]. Curcumin showed a competitive type of inhibition

Copyright: The authors. This article is an open access article licensed under the terms of the Creative Commons Attributin License (http:// creative commons.org/licenses/by/2.0) which permits unrestricted use, distribution and reproduction in any medium, provided the work is properly cited. towards CYP1A2, CYP3A4, whereas a non-competitive inhibition was observed with respect to CYP2D6 and CYP2C9 [8]. Hence, there was a possibility of curcumin for the metabolic inhibition of GL, which is metabolized by CYP3A4 microsomal liver enzymes [9-11].

The aim of this study was to highlight the clinical interactions between herbal remedy (curcumin) and prescribed drug (GL).

\section{Materials and Methods}

GL was administered as the suspension in freshly prepared $2 \% \mathrm{w} / \mathrm{v}$ gum acacia. Pure standard Curcumin was administered in olive oil as a vehicle.

\section{Ethical approval}

Male albino rats of Sprague Dawley strain weighing around 200-250 g were procured from National Institute of Nutrition (NIN), Hyderabad. The experimental protocol was approved by the Institutional Animal Ethics Committee.

\section{Experimental design}

The study was carried out on 12 diabetic rats that were randomly divided into two groups comprising 6 rats in each group for single and multiple dose kinetics of GL on day 1 following curcumin pre-treatment and at the end of continuous daily administration of curcumin and GL for 2 months. 
Group 1: GL (6 mg/kg po once daily) treatment in diabetic rats [12]

Group 2: GL (as above) + curcumin $(50 \mathrm{mg} / \mathrm{Kg}$ po) once daily in diabetic rats [13]

Rats were induced diabetes by intraperitoneal injection of streptozotocin@ $40 \mathrm{mg} / \mathrm{kg}$ body weight. The rats were provided with glucose water for $24 \mathrm{~h}$ to prevent hypoglycemia. After $72 \mathrm{~h}$, blood samples were collected for glucose estimation. Rats with blood glucose value of $>250 \mathrm{mg} / \mathrm{dl}$ ( $72 \mathrm{~h}$ after streptozotocin administration) were included in the study $(\mathrm{n}=6)$. Treatment protocols were initiated from day 2 post-confirmation of diabetes (day 5 post-streptozotocin administration) and were continued for 8 weeks.

\section{Blood collection for pharmacokinetic (PK) studies}

Blood (approximately $500 \mu \mathrm{l}$ ) was collected from retro-orbital plexus at $0,5,10,20,40$, and $90 \mathrm{~min}$, and $2 \mathrm{~h}, 4 \mathrm{~h}, 8 \mathrm{~h}, 12 \mathrm{~h}$, and $24 \mathrm{~h}$ after oral administration of GL in required dose into heparinized containers and plasma was separated by centrifugation at 3000 RPM for $15 \mathrm{~min}$ and stored at $-20^{\circ} \mathrm{C}$ till analysis.

\section{High-performance liquid chromatography (HPLC) assay of GL in rat plasma}

GL was extracted from plasma samples by liquid-liquid extraction technique. Methanol was added to plasma at a ratio of 1:1 and thoroughly mixed by vortexing for $30 \mathrm{~s}$. The mixture was then centrifuged at $5000 \mathrm{rpm}$ for $10 \mathrm{~min}$. The clear supernatant thus obtained was transferred into microcentrifuge tubes following filtration through $0.2 \mu \mathrm{HN}$ nylon membrane filter. A $20 \mu \mathrm{l}$ of filtrate was injected manually into HPLC with dual wavelength UV detector (SPD20A) and LC solution ${ }^{\circledR}$ software for data analysis. A reverse phase $\mathrm{C}_{18}$ Column $(250 \times 4.5 \mathrm{~mm}$, particle size $5 \pm 0.3 \mu \mathrm{m}$, pore diameter $100 \pm 10 \AA$, Phenomenax ${ }^{\circledR}$, (USA) served as stationary phase. Mobile phase consisted of $0.1 \%$ orthophosphoric acid: methanol: acetonitrile mixed at a ratio of (20:50:30) volumes. The flow rate of mobile phase was maintained @ $1 \mathrm{ml}$ per minute. The detection wavelength was set at $240 \mathrm{~nm}$ (UV). The plasma samples were analyzed for $8 \mathrm{~min}$ at room temperature. There were no interfering peaks in the chromatogram at the retention time $\left(\mathrm{R}_{\mathrm{t}}=\right.$ $6.00 \pm 0.82)$ of GL.

\section{PK analysis}

The plasma concentration-time profile of GL of each animal was used to determine its PK. The PK data of GL was subjected to compartmental analysis. Following oral administration, the plasma levels of GL were described by non-compartmental analysis of data. Different PK parameters were analyzed using the software PK solver 2.0 [14].

\section{Statistical analysis}

Single and multiple dose PK data were statistically analyzed by applying non-parametric test while other data were subjected to statistical analysis by applying one-way ANOVA using Statistical Package for Social Sciences (SPSS) version 15.0. Differences between means were tested using Duncan's multiple comparison test and significance level was set at 0.05 .

\section{Results}

Single dose administration of GL in Group 1 resulted in detectable concentration of the drug $(2.85 \pm 0.02 \mathrm{mg} / \mathrm{ml})$ at $10 \mathrm{~min}$ and the peak plasma level of $5.62 \pm 0.05 \mathrm{mg} / \mathrm{ml}$ was achieved at $2 \mathrm{~h}$ (Table- 1 and Figure-1). Elimination rate constant, elimination halflife, AUC0-t, mean residence time (MRT), Vdss, and CL $\beta$ were $0.05 / \mathrm{h}, 10.03 \pm 0.05 \mathrm{~h}, 83.49 \pm 0.84 \mathrm{mg} / \mathrm{ml} \mathrm{h}$, $14.89 \pm 0.23 \mathrm{~h}, 1.54 \pm 0.01 \mathrm{~L} / \mathrm{kg}$ and $0.07 \pm 0.00 \mathrm{~L} / \mathrm{kg} / \mathrm{h}$, respectively (Table-2). Curcumin pretreated rats (Group 2) showed elimination rate constant, elimination half-life, AUC0-t, MRT, Vd(area), and CL $\beta$ were $0.04 / \mathrm{h}, 10.42 \pm 0.10 \mathrm{~h}, 87.86 \pm 1.94 \mathrm{mg} / \mathrm{mlh}$, $18.80 \pm 0.83 \mathrm{~h}, 1.84 \pm 0.05 \mathrm{~L} / \mathrm{kg}$, and $0.07 \pm 0.00 \mathrm{~L} / \mathrm{kg} / \mathrm{h}$, respectively (Table-2)

Multiple oral administration of GL $(6 \mathrm{mg} / \mathrm{kg})$ in rats resulted in detectable concentration of the drug $(3.27 \pm 0.02 \mathrm{mg} / \mathrm{ml})$ at $10 \mathrm{~min}$ and the peak plasma level of $5.99 \pm 0.05 \mathrm{mg} / \mathrm{ml}$ was achieved at $2 \mathrm{~h}$ (Table-3 and Figure-2). Elimination rate constant, elimination half-life, $\mathrm{AUC}_{0-\mathrm{t}}, \mathrm{MRT}, \mathrm{V}_{\mathrm{dss}}$ and $\mathrm{CL}_{\beta}$ were $0.04 / \mathrm{h}$, $10.23 \pm 0.02 \mathrm{~h}, 92.41 \pm 0.84 \mathrm{mg} / \mathrm{ml} \mathrm{h}, 16.60 \pm 0.24 \mathrm{~h}$, $1.55 \pm 0.02 \mathrm{~L} / \mathrm{kg}$, and $0.07 \pm 0.00 \mathrm{~L} / \mathrm{kg} / \mathrm{h}$ respectively (Table-4). Curcumin pre-treated rats, detectable

Table-1: Mean plasma concentration of $\mathrm{GL}(\mu \mathrm{g} / \mathrm{ml})$ following pre-treatment with curcumin in diabetic rats during single dose PK studies.

\begin{tabular}{lcc}
\hline Time (h) & DM+GL & DM+GL+Curcumin \\
\hline 0.16 & $2.85 \pm 0.02$ & $2.69 \pm 0.04$ \\
0.33 & $3.45 \pm 0.03$ & $3.25 \pm 0.05$ \\
0.66 & $4.54 \pm 0.06$ & $4.39 \pm 0.11$ \\
1.5 & $4.85 \pm 0.07$ & $5.07 \pm 0.08$ \\
2.0 & $5.62 \pm 0.05$ & $5.48 \pm 0.07$ \\
4.0 & $5.12 \pm 0.04$ & $5.08 \pm 0.10$ \\
8.0 & $4.14 \pm 0.04$ & $4.24 \pm 0.07$ \\
12.0 & $3.17 \pm 0.03$ & $3.53 \pm 0.11$ \\
24.0 & $2.04 \pm 0.04$ & $2.39 \pm 0.10$ \\
\hline
\end{tabular}

Values are Mean $\pm S E(n=6), S E=S t a n d a r d$ error, $\mathrm{GL}=$ Glibenclamide, $\mathrm{PK}=$ Pharmacokinetic

Table-2: Pharmacokinetic parameters of GL following pre-treatment with curcumin in diabetic rats during single dose PK studies.

\begin{tabular}{lcc}
\hline Parameter & DM+GL & DM+GL+Curcumin \\
\hline Cmax $(\mu \mathrm{g} / \mathrm{ml})$ & $5.63 \pm 0.05$ & $5.48 \pm 0.07$ \\
Tmax $(\mathrm{h})$ & 2 & 2 \\
Elimination rate & $0.05 \pm 0.00$ & $0.04 \pm 0.00$ \\
${\text { Constant }\left(\mathrm{h}^{-1}\right)}$ & $10.03 \pm 0.05$ & $10.42 \pm 0.10^{*}$ \\
$\mathrm{~T}_{1 / 2 \beta}(\mathrm{h})$ & $83.49 \pm 0.84$ & $87.86 \pm 1.94$ \\
AUC $_{(0-\mathrm{t})}(\mu \mathrm{g}-\mathrm{h} / \mathrm{ml})$ & $14.89 \pm 0.23$ & $18.80 \pm 0.83^{*}$ \\
$\mathrm{MRT}^{(\mathrm{h})}$ & $1.54 \pm 0.01$ & $1.84 \pm 0.05^{*}$ \\
$\mathrm{~V}_{\mathrm{d}(\text { area) }}(\mathrm{L} / \mathrm{kg})$ & $0.07 \pm 0.00$ & $0.07 \pm 0.00$ \\
$\mathrm{CL}_{\mathrm{B}}\left(\mathrm{L} / \mathrm{kg} / \mathrm{h}^{-1}\right)$ &
\end{tabular}

$\mathrm{SE}=$ Standard error, $\mathrm{GL}=$ Glibenclamide, $\mathrm{PK}=$ Pharmacokinetic, *Significant variation at $\mathrm{p} \leq 0.05$ Duncan's multiple comparison test, values are mean $\pm \operatorname{SE}(n=6)$ 


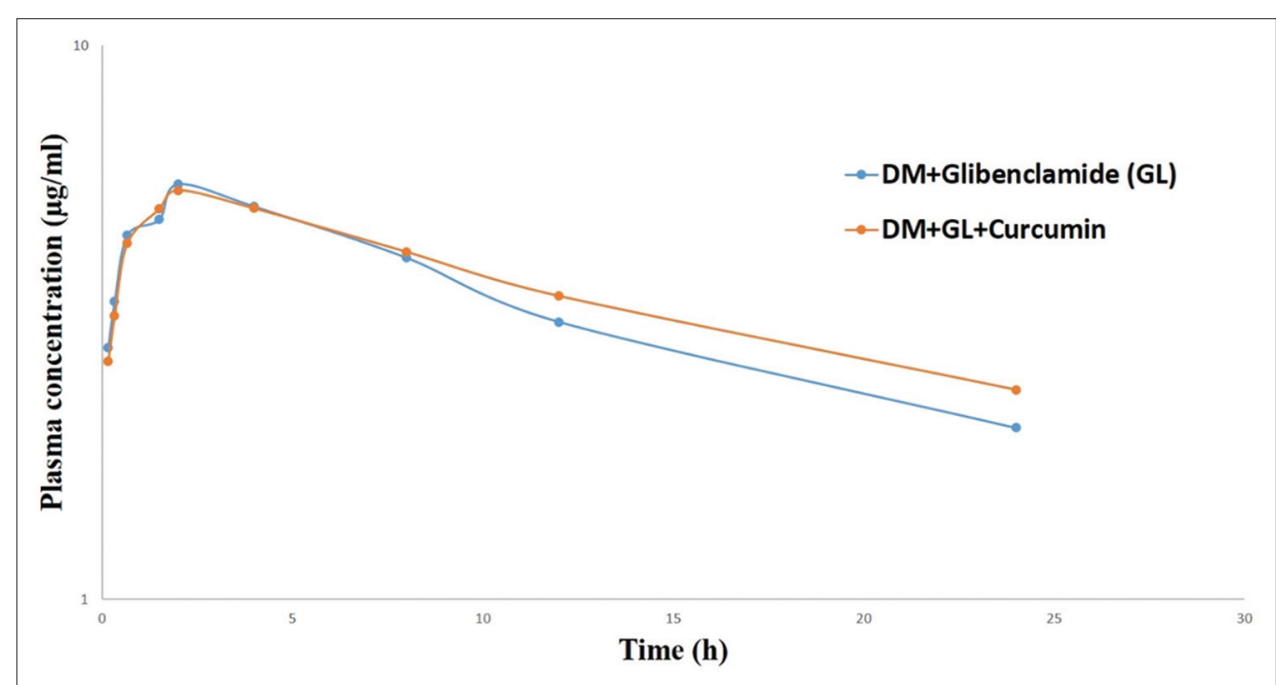

Figure-1: Plasma concentration of glibenclamide $(\mu \mathrm{g} / \mathrm{ml})$ following pre-treatment with curcumin in diabetic rats during single dose pharmacokinetic studies.

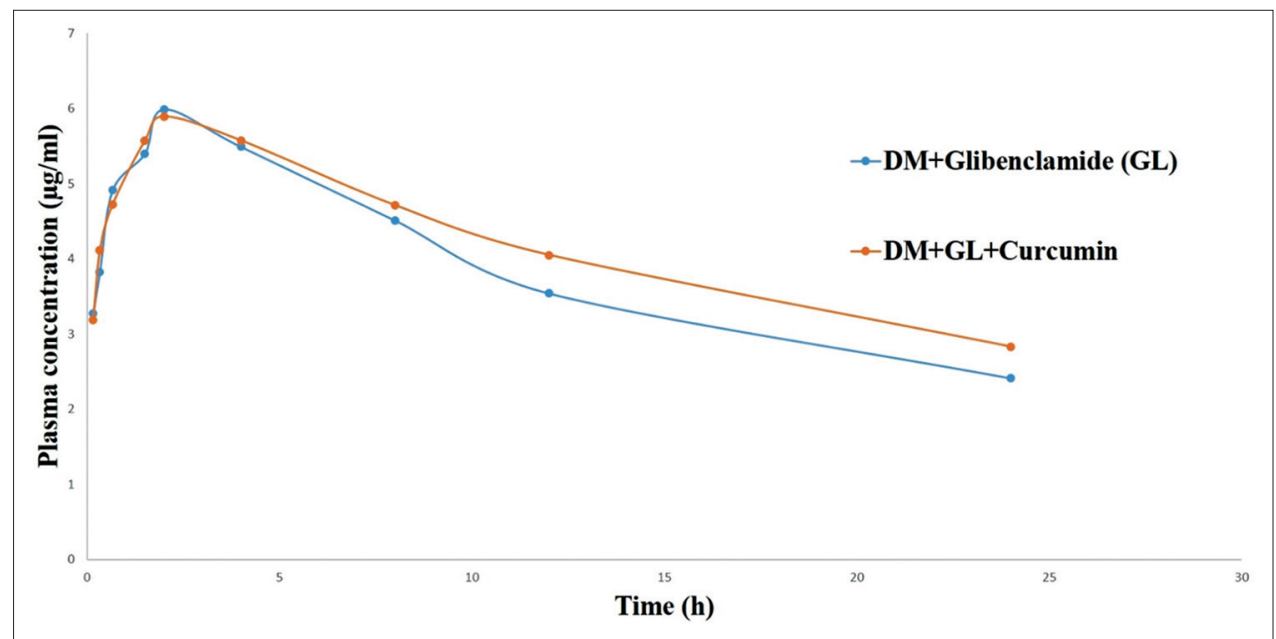

Figure-2: Plasma concentration of glibenclamide $(\mu \mathrm{g} / \mathrm{ml})$ following pre-treatment with curcumin in diabetic rats during multiple-dose pharmacokinetic study.

Table-3: Mean plasma concentration of GL $(\mu \mathrm{g} / \mathrm{ml})$ following pre-treatment with curcumin in diabetic rats during multiple dose PK studies.

\begin{tabular}{lcc}
\hline Time (h) & DM+GL & DM+GL+Curcumin \\
\hline 0.16 & $3.27 \pm 0.02$ & $3.19 \pm 0.03$ \\
0.33 & $3.82 \pm 0.03$ & $4.11 \pm 0.07$ \\
0.66 & $4.91 \pm 0.06$ & $4.72 \pm 0.23$ \\
1.5 & $5.4 \pm 0.07$ & $5.57 \pm 0.11$ \\
2.0 & $5.99 \pm 0.05$ & $5.89 \pm 0.12$ \\
4.0 & $5.49 \pm 0.04$ & $5.57 \pm 0.14$ \\
8.0 & $4.51 \pm 0.04$ & $4.71 \pm 0.10$ \\
12.0 & $3.54 \pm 0.03$ & $4.05 \pm 0.11$ \\
24.0 & $2.41 \pm 0.04$ & $2.83 \pm 0.11$ \\
\hline
\end{tabular}

Values are mean $\pm S E(n=6), S E=S t a n d a r d$ error, $\mathrm{GL}=$ Glibenclamide, $\mathrm{PK}=$ Pharmacokinetic

concentration of the drug was $3.19 \pm 0.03 \mathrm{mg} / \mathrm{ml}$ at $10 \mathrm{~min}$ and the peak plasma level of $5.89 \pm 0.12 \mathrm{mg} / \mathrm{ml}$ was achieved at $2 \mathrm{~h}$ (Table-3 and Figure-2). Elimination rate constant, elimination half-life, $\mathrm{AUC}_{0-t}, \mathrm{MRT}, \mathrm{V}_{\mathrm{dss}}$ and $\mathrm{CL}_{\beta}$ were $0.034 / \mathrm{h}, 10.63 \pm 0.10 \mathrm{~h}, 99.82 \pm 2.02 \mathrm{mg} / \mathrm{ml} \mathrm{h}$, $21.89 \pm 1.03 \mathrm{~h}, 1.82 \pm 0.01 \mathrm{~L} / \mathrm{kg}$, and $0.06 \pm 0.00 \mathrm{~L} / \mathrm{kg} / \mathrm{h}$, respectively (Table-4).
Table-4: Pharmacokinetic parameters of GL following pre-treatment with curcumin in diabetic rats during multiple dose PK studies.

\begin{tabular}{lcc}
\hline Parameter & DM+GL & DM+GL+Curcumin \\
\hline Cmax $(\mu \mathrm{g} / \mathrm{ml})$ & $5.99 \pm 0.05$ & $5.89 \pm 0.12$ \\
Tmax $(\mathrm{h})$ & 2 & 2 \\
Elimination rate & $0.042 \pm 0.00$ & $0.034 \pm 0.00$ \\
${\text { Constant }\left(\mathrm{h}^{-1}\right)}$ & $10.23 \pm 0.02$ & $10.63 \pm 0.10 *$ \\
$\mathrm{~T}_{1 / 2 \beta}(\mathrm{h})$ & $92.41 \pm 0.84$ & $99.82 \pm 2.02$ \\
AUC $_{(0-\mathrm{t})}(\mu \mathrm{g}-\mathrm{h} / \mathrm{ml})$ & $16.60 \pm 0.24$ & $21.89 \pm 1.03 *$ \\
$\mathrm{MRT}^{(\mathrm{h})}$ & $1.55 \pm 0.02$ & $1.82 \pm 0.01$ \\
$\mathrm{~V}_{\mathrm{d}(\text { area) }}(\mathrm{L} / \mathrm{kg})$ & $0.07 \pm 0.00$ & $0.06 \pm 0.00$ \\
$\mathrm{CL}_{\mathrm{B}}(\mathrm{L} / \mathrm{kg} / \mathrm{h})$ &
\end{tabular}

*Significant variation at $\mathrm{P} \leq 0.05$ Duncan's multiple comparison test, Values are Mean $\pm \operatorname{SE}(n=6)$, $\mathrm{SE}=$ Standard error, $\mathrm{GL}=$ Glibenclamide, $\mathrm{PK}=$ Pharmacokinetic

\section{Discussion}

In this study, we investigated the PK interactions of curcumin with GL, which is metabolized by CYP3A4 microsomal liver enzymes. GL is 
metabolized by CYP3A4 and is a substrate for intestinal P-glycoprotein [15]. Curcumin could also give rise to drug interactions as it has been reported to inhibit both the function and expression of P-gp [16]. Several in vitro studies reported the inhibition of CYP 450s, especially CYP3A4, CYP1A2, and CYP2C9 by curcumin [8].

In single-dose study, there was a significant increase in the $\mathrm{t}_{1 / 2 \beta}(18.80 \pm 0.83 \mathrm{~h})$ and MRT $(1.84 \pm 0.05 \mathrm{~h})$ values in curcumin pre-treated rats when compared to GL alone treated group. Similarly, $\mathrm{V}_{\text {dss }}(1.82 \pm 0.01 \mathrm{~L} / \mathrm{kg})$ was significantly increased in curcumin pre-treated rats as compared to GL alone treated group. Similarly in multiple dose study, there was a significant increase in the $t_{1 / 2}$ and MRT in curcumin pre-treated group, compared to GL used alone. GL is extensively metabolized by CYP3A4 and is also a substrate for P-gp. Organic anion transport proteins are reported to be responsible for transport of large number of endogenous and xenobiotic compounds across cell membranes [17].

The most useful term in PKs is the apparent volume of distribution at steady state or $\mathrm{V}_{\mathrm{dss}}$. It gives an idea of the relative degree of drug binding in the blood and extravascular space. Increased $V_{\text {dss }}$ may be due to increased penetration of drug which resulted in prolonged $t_{1 / 2}$ and MRT [18].

The increase in $t_{1 / 2}$, MRT, and $V_{\text {dss }}$ may be due to the inhibitory effect of curcumin on intestinal CYP34A in intestine and liver cells, thus decreasing the metabolism of GL.

\section{Conclusion}

The present study concluded that curcumin pre-treatment to diabetic rats in single and multiple dose study increased the $t_{1 / 2}$, MRT, and $\mathrm{V}_{\text {dss }}$ of GL suggesting a synergistic $\mathrm{PK}$ profile.

\section{Authors' Contributions}

PRSD supervised the overall research work. PRSD, CSVSK, and GB performed the study. AGR and GSR participated in draft and revision of the manuscript. All authors read and approved the final manuscript.

\section{Acknowledgments}

The authors are thankful to the Associate Dean, College of Veterinary Science, Rajendranagar, Hyderabad for providing the necessary facilities and fund for this study.

\section{Competing Interests}

Authors declare that they have no competing interests.

\section{References}

1. Sarah, W., Bchir, M.B., Gojka, R., Anders, G., Richard, S. and Hilary, K. (2004) Global prevalence of diabetes.
Diabetes Care, 27: 1047-1053.

2. Christina, L.A. (2010) Sulfonylurea pharmacogenomics in type 2 diabetes: The influence of drug target and diabetes risk polymorphisms. Exp. Rev. Cardiovasc. Ther., 8(3): 359-372.

3. Marchetti, P., Gianerelli, R., Carlo, A.D. and Navalesi, R. (1991) Pharmacokinetic optimization of oral hypoglycaemic therapy. Clin. Pharmacokinet., 21: 308-317.

4. Zhou, L., Naraharisetti, S.B., Liu, L, Wang, H., Lin, Y.S. Isoherranen, N., Unadkat, J.D., Hebert, M. and Mao, Q. (2010) Contributions of human cytochrome P450 enzymes to glyburide metabolism. Biopharm. Drug Dispos., 31: 228-242.

5. Dulbecco, P. and Savarino, V. (2013) Therapeutic potential of curcumin in digestive diseases, World J. Gastroenterol., 19(48): 9256-9270.

6. Meng, B., Li, J. and Cao, H. (2013) Antioxidant and anti-inflammatory activities of curcumin on diabetes mellitus and its complications. Curr. Pharm. Des., 19(11): 2101-2113.

7. Nowack, R. (2008) Herb-drug interactions in nephrology: Documented and theoretical. Clin. Nephrol., 69(5): 319-325.

8. Cho, Y.A., Lee, W. and Choi, J.S. (2012) Effects of curcumin on the pharmacokinetics of tamoxifen and its active metabolite, 4-hydroxy tamoxifen, in rats: Possible role of CYP3A4 and P-glycoprotein inhibition by curcumin. Pharmazie, 67(2): 124-130.

9. Lee, C.K., Ki, S.H. and Choi, J.S. (2011) Effects of oral curcumin on the pharmacokinetics of intravenous and oral etoposide in rats: Possible role of intestinal CYP3A and P-gp inhibition by curcumin. Biopharm. Drug Dispos., 2011;32(4): 245-251.

10. Volak, L.P., Ghirmai, S., Cashman, J.R. and Court. M.H. (2008) Curcuminoids inhibit multiple human cytochromes P450, UDP-glucuronosyl transferase (UGT), and sulfotransferase enzymes, whereas piperine is a relatively selective CYP3A4 inhibitor. Drug Metab. Dispos., 36: 1594-1605.

11. Mach, C.M., Chen, J.H., Mosley, S.A., Kurzrock, R. and Smith, J.A. (2010) Evaluation of liposomal curcumin cytochrome p450 metabolism. Anticancer Res., 30(3): 811-814.

12. Palanivel, V., Shafi, M. and Kumar, S.K.L. (2013) Antidiabetic and hypolipidemic activities of Momordica tuberosa unripe fruit extract on diabetic induced rats. Int. $J$. Adv. Pharm. Gen. Res., 1: 33-40.

13. Menozzi, A.,Pozzoli, C., Poli, E., Martelli, M., Martelli, L., Zullian, C. and Bertini, S. (2009) Effects of oral curcumin on indomethacin-induced small intestinal damage in the rat. Drug Discov. Ther., 3(2): 71-76.

14. Gibaldi, M. and Perrier, D. (1982) Pharmacokinetics. $2^{\text {nd }}$ ed. Marcel Dekker, New York.

15. Srirangam, P. and Vidya, S.J. (2010) Modulation of the P-Glycoproein mediated intestinal secretion of glibenclamide: In vitro and In vivo assessments. J. Young Pharm., 2(4): 379-383.

16. Zhang, W., Chin Tan, T.M. and Lim, L.Y. (2007) Impact of curcumin-induced changes in P-glycoprotein and CYP3A expression on the pharmacokinetics of peroral celiprolol and midazolam in rats. Drug Metab. Dispos., 35(1): 110-115.

17. Miller, D.S. (2014) Sphingolipid signalling reduces basal P-Glycoprotein activity in renal proximal tubule. $J$. Pharmacol. Exp. Ther., 348(3): 459-464.

18. Sajid, H.A.M., Khan, I.U., Shah, S.N.H., Asghar, S., Massud, A., Qadir, M.I. and Akbar, A. (2010) Sustained release hydrophilic matrices based on xanthan gum and hydroxypropyl methylcellulose: Development, optimization, in vitro and in vivo evaluation. J. Appl. Pharm., 4: 89-103. 